\title{
Biomimetic Approach for the Production of 3D Woven Spherical Composite Applied in Apparel Protection and Performance
}

\author{
Yuyuan Shi $^{1}$ (D) . Lindsey Waterton Taylor $^{1}$ (D) $\cdot$ Vien $^{\text {Cheung }}{ }^{1}$ (D) \\ Abu Sadat Muhammad Sayem ${ }^{2}$ (D)
}

Received: 14 May 2021 / Accepted: 29 June 2021 /Published online: 31 July 2021

(C) The Author(s) 2021

\begin{abstract}
Current sports bras are typically manufactured via a cut and sew process resulting in a high volume of post-production material waste. Seams derived from this cut and sew process are known to irritate the skin during exercise. This irritant discomfort seriously affects the dynamic comfort during exercise, hindering limb movement and displacement of the female breast. It implies a need for an alternative textile manufacturing process for a seamless sportswear-sports bra to combine the surface aesthetics with biomimetics together with anthropometry and ergonomic data. Tailoring the two yarn interlocking directions $\left(0 / 90^{\circ}\right)$ within the compound structure of a multilayer multilevel weave architecture provides a construction process to the production, the weaving, of seamless $3 \mathrm{D}$ woven spherical forms. Seamlessly shaped wovens in this paper are underpinned by biomimetic anthropometry and real-time data to produce variable spherical forms that mould and support a given set of 3D geometries. Upon completion of the weave generation using specialised weave software, the production parameters are completed upon transfer to the combined weaving technology, Mageba-Staubli Unival 100 (MS-100). The 2D on-loom woven fabric converts to a 3D shape upon removal and by pulling-pushing-unfolding the woven fabric (2D-to3D). The scope of end applications within the sportswear-sports bra sector (but not limited to) enables a framework for the generic design geometries and production principles.
\end{abstract}

Keywords 3D weaving $\cdot$ Spherical composites $\cdot$ Ergonomic $\cdot$ Sportswear $\cdot$ CAD/CAM

\section{Introduction}

Sportswear is an item of unique protective clothing worn for body appearance and safety reasons during sports and physical exercise. It generally comprises performance wear, outdoor wear, and sports-inspired wear [1]. The sports bra is the closest fitting apparel item

Yuyuan Shi

sdys@leeds.ac.uk

1 3D Weaving Innovation Centre, School of Design, University of Leeds, Leeds LS2 9JT, UK

2 Manchester Fashion Institute, Manchester Metropolitan University, Manchester M15 6BG, UK 
[2] designed for reducing breast movements and alleviate post-sporting discomfort and pain $[3,4]$ during exercise. However, a common complaint is cyclic and non-cyclic pain during exercise $[3,5,6]$ leading to a varying range of discomfort. This may considerably affect women's health and quality of life and increase the need for breast reduction surgery. It has been reported that up to $69 \%$ of females suffer from discomfort due to wearing poorly fitting lingerie [7]. Well-fitting sports bras significantly relieved breast motion pain [3] while jogging [8] and running [9].

Two of the drivers for re-engineering the current manufacturing approach of sportswearsports bras are to reduce:

- the textile process-production labour time to post-production material waste, typically $5 \%$-to-15\% [10];

- seams derived from the cut and sew process [10] and subsequent irritation to the skin.

The direct contact between textiles and skin is a variable in the design for textiles, and design for textile production and product. Tactility and dynamic comfort are imperative during movement/exercise [11]. With consideration to the inherent seams concluding from the cut and sew textile process to textile product, the seamed areas result in additional fabric density. Without consideration to tactility and dynamic comfort in the design and manufacturing process such proximity apparel/lingerie to the skin will continue to hinder limb movement [12], for instance, frequent contraction of the joint parts of the human body during exercise [13] and displacement of the female breast [6, 14]. Discontinuity of fibre-yarn due to the cutting of textiles reduces the level of reinforcement and ultimately protection [15].

Correspondingly, body mapping is an important principle in sportswear design and engineering [10]. It means function variations of different body regions during exercises, such as thermal regulation [16, 17] and skin temperature adjusting [18], breast support, or restraint. For example, sports bras require stable structures and perfect solid shape to support and restrict breast movement [5] at the same time. Although knitting technology is the primary textile manufacturing process [1] used for sportswear skin layer, knitted fabric has lower stiffness because of the inherent looped structure [19]. Thus, the knitting fabric applied in the sports bra needs to be cut and sewn to obtain shapes, and a 3D polymer solid model needs to be added between the outer and inner knitting fabric bra to get the support or limit the displacement functions [10]. 3D woven angle-interlock weave architectures employed in previous research of seamless female body armour [15, 20] suggested the need for 3D shaped weaving methods to optimise, during the weaving cycle, the shaping in the front of the body armour to fit the female upper body form comfortably.

These sustainability issues and dynamic comfort requirements disclose the needs for seamless forms with tailored tactility and functional areas. The latest 3D conventional weaving technology permits the interlocking of the yarns in the $\mathrm{X}$ (longitudinal-warp), $\mathrm{Y}$ (cross-weft), and Z (vertical- through-thickness) directions. These three interlocking directional yarns are then tailored within the amalgamated weave architectures. Associated to multilayer (warp) multilevel (weft) wovens enables specific drape, support and movement. A hybrid of fibre-yarn types within the compositing of the 3D woven seamless fitting bra enables the optimisation of such undergarments for physical-active sportswear use.

Anthropometric measurement data is a significant influencing factor and basis for producing the fitting undergarments and sportswear-sports bras. Since the breast is a complex $3 \mathrm{D}$ geometry [21] without bone and muscle [6], it is difficult to manually measure the 3D 
shape data, such as breast depth and breast width. A large and growing body of literature focuses on utilising a three-dimensional (3D) human scanner, investigating anthropometric breast measurements for improving fitting issues of the bra. Lee et al. [22] scanned unclothed breasts using phase-shifting moire and got a reliable breast boundary, thereby providing new shape parameters for the breast form. Female breast shapes were categorised to define breast shape and improve the fitting issues caused by the inaccurate shape and size systems [23]. Shi et al. [24] analysed 20 measured variables of the bust area and upper torso obtained by the 3D human scanner to propose two auxiliary criteria for enhancing the Chinese bra size system. Besides these mature measurement applications of the 3D human scanner, "3D-to-2D" pattern flattening technique, the 3D curved surface is converted to a 2D plane pattern developed for clothing manufacture [25]. Sayem et al. [26] investigated the effects of link-lengths and vertex angles on 3D virtual clothing model prototyping and flattening speed. The 3D-to-2D pattern flattening from 3D scanning mannequins of loose-fitting [27, 28] and trouser [29] and were developed to shorten the manpower involvement and reduce the time costs. All these works emphasized the requirements of manufacture composited driven by the ergonomic real-time data.

Positioning the work within the sportswear-sports bra market enables a framework for the range of generic design geometries. For the bra design and manufacture, the 3D-to-2D geometry data basis is the 3D scanning real-time data, this precisely limits the size of the 3D composite. Therefore, before the successful manufacture of the sports bra, the shaped spherical forms formed by the real-time data should be explored initially. This research employs the latest in weaving technology developing 3D woven spherical forms based on the origami principle used in a multifaceted textile end application such as medical, protection, and composites industry where support, protection and performance are also of importance in associated materials.

\section{Materials and Methods}

The whole 3D-to-2D-to-3D process in this research was identified as two parts-3D complex spherical surface geometries converted into a seamless 2D graphical pattern based on the origami principle (3D-to-2D) using a cross-platform CAD system and 2D geometries with appropriate weave architectures transmitted back to 3D seamless woven spherical composites (2D-to-3D). The 3D geometries based on real-time data are converted into 2D graphical schematics with segmentations and artificial boundary lines. This converted 2D graphical schematics is additionally drawn in Bok Garment CAD System (Shenzhen Bok Investment Co., Limited., Bok, V13) with marked reference points. EAT 3D WEAVE COMPOSITE software (EAT GmbH, "The DesignScope Company", EAT 3D), the secondary CAD/CAM process was used to transfer/draw the 2D pattern; multilayer and multilevel weave architectures applied together with CAM data for production using the Mageba multishuttle weaving machine and Staubli UNIVAL 100 jacquard harness (MS-100). Polyester is selected as the weaving yarns of picks and ends, which is most widely used in sportswear, due to its durability, anti-wrinkle, and anti-stretch properties [1]. Combining the latest in advanced weaving machines, Mageba multi-shuttle with the latest in jacquard technologies, Staubli Unival 100 (MS-100) enabled the successful stages of geometric flattening of a given form for design for production to product/prototype: 3D-to-2D-to-3D woven spherical forms. The inclusion of advancing mechanics and motions of the MS-100, 
production parameters and their inclusion within the design relative to the weaving cycle permits ongoing developments and advancing the origami principles to more complex components that comprises a seamless woven sportswear-sports bra.

The initial dome shape creation for use in the origami principle geometry process, as shown in Fig. 1, this essential reference hemisphere is created from a sphere with radius $r_{1}$. The hypothesis was made that the hemisphere's surface was divided into six parts via the red, green, and blue split lines (Fig. 1a), so the apex angle of each spherical portion is $60^{\circ}$. Since the sphere was equally divided into six parts, the remaining sections were obtained by cloning the sample piece. The $\operatorname{arc} C B$ is identified as the sample, and the circle on the same plane of the arc $C B$ was taken as the reference circle with radius $r_{1}$. The rectangular coordinate system was established with point $\mathrm{C}$ as the origin (see Fig. 1b). The $\operatorname{arc} C B$ and the reference circle is rotated to intersect the y-axis, keeping the size unchanged in this process, the rotated arc is denoted as $\operatorname{arc} C B_{1}$. In Fig. 1a and b, $l_{C D} \perp l_{B_{1} A}$,

$$
\begin{gathered}
l_{O A}=l_{O B}=l_{O C}=r_{1} \\
l_{C B}=l_{C B_{1}}=l_{C A} \\
l_{D B_{1}}=l_{D A}=l_{B_{1} A} / 2 \\
\operatorname{arc~} C B=\operatorname{arc~} C B_{1}=\operatorname{arc} C A=\frac{\pi}{2} r_{1}
\end{gathered}
$$

where $l_{O A}$ represents the Line Segment OA, similarly, other abbreviations also represent line segments. The $\operatorname{arc} C B_{1}$ is rotated to lay the Point $\mathrm{D}$ is on the $y$-axis to get a vertical symmetrical figure to facilitate subsequent operations. The final reference $\operatorname{arc} C B_{2}$ and reference polygon $\left(\mathrm{plg}_{\mathrm{CB}_{2} \mathrm{~A}}\right)$ is obtained by repeating the same previous operation (see Fig. 1c and d).

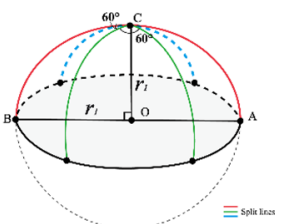

(a)

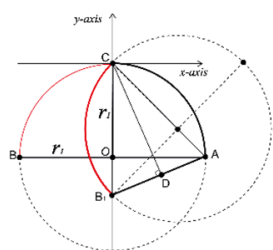

(b)
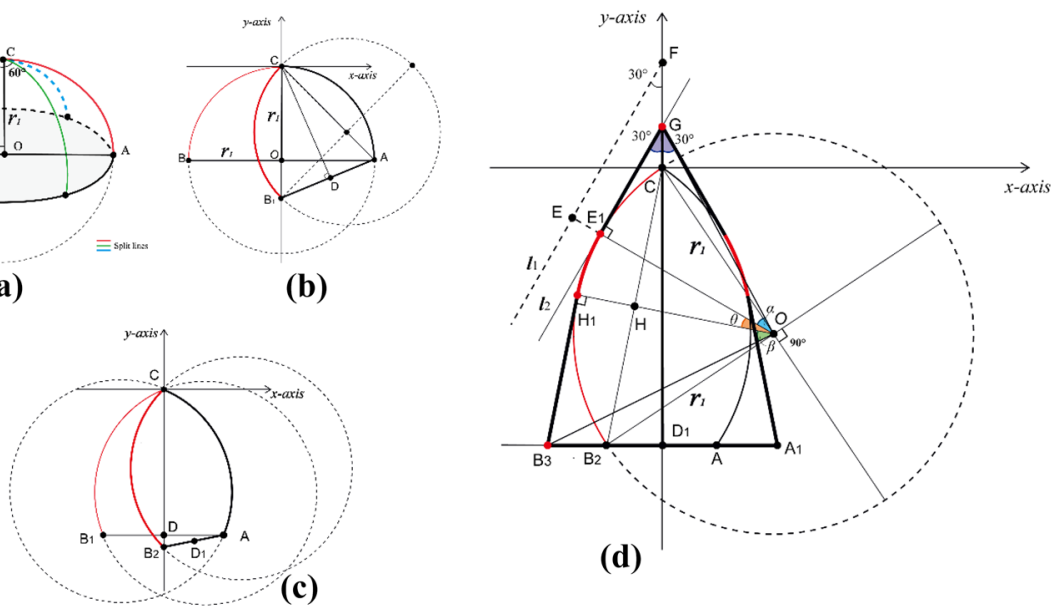

Fig. 1 3D-to-2D geometry process (a) The hemisphere schematic diagram (b) The reference $\operatorname{arc} C B$ and circle schematic diagram (c) The reference $\operatorname{arc} C B_{2}$ and circle schematic diagram (d) The flattened 2D geometry 
In Fig. 1c and d, $l_{1} \| l_{2}, l_{O E_{1}} \perp l_{G E_{1}}, l_{O H_{1}} \perp l_{H_{1} B_{3}}$,

$$
\begin{gathered}
l_{O C}=l_{O E_{1}}=l_{O H_{1}}=l_{O B_{2}}=r_{1} \\
\operatorname{arc} C B_{2}=\operatorname{arc} C A=\frac{\pi}{2} r_{1} \\
l_{G E_{1}}=r_{1} \tan \alpha \\
\operatorname{arc} E_{1} H_{1}=\theta \pi r_{1} / 180 \\
l_{H_{1} B_{3}}=r_{1} \tan \beta \\
p l_{G E_{1} H_{1} B_{3}}=r_{1}(\tan \alpha+\theta \pi / 180+\tan \beta)
\end{gathered}
$$

Point $\mathrm{D}_{1}$ is the midpoint of the $l_{B_{2} A}$, and the $\operatorname{arc} C B_{2}$ is equal to the $\operatorname{arc} C A$, thus the polygon $\left(\operatorname{plg}_{\mathrm{CB}_{2} A}\right)$ is a symmetrical figure with the $y$-axis as the symmetry axis. The flattening process using arc $C B_{2}$ as the flattened sample to obtain the polyline ( $p l_{G E_{1} H_{1} B_{3}}$ ), the completed version geometry $\left(\operatorname{plg}_{G B_{3} A_{1}}\right)$ with the angle $60^{\circ}$ is obtained via symmetrical copying, taking the $y$-axis as the symmetry axis. As a result, the polygon $\left(p l g_{G B_{3} A_{1}}\right)$ is the acquired flatten geometry through the 3D-to-2D process.

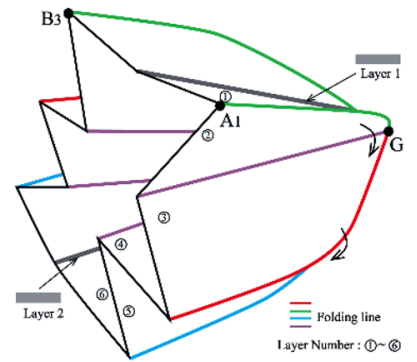

(a)

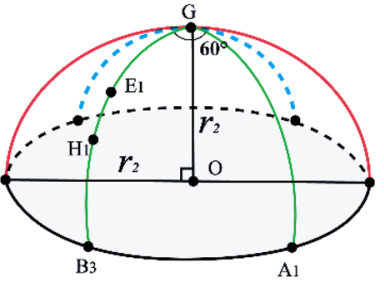

(b)

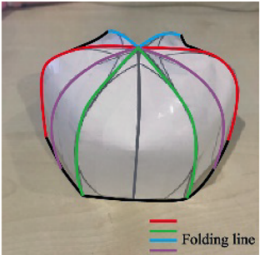

(d)

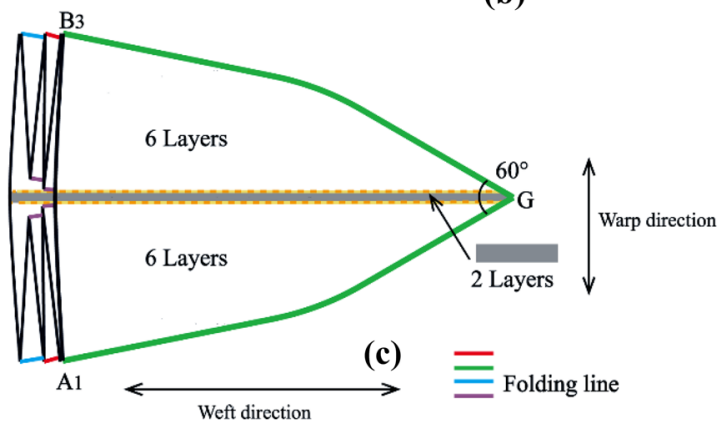

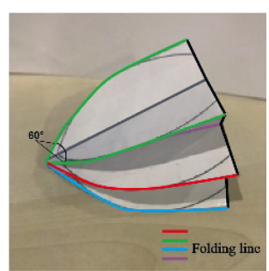

(e)

Fig. 2 The folding process (a) The folded hemisphere schematic diagram (b) The unfolding hemisphere schematic diagram based on obtained 2D flattened polygon $\left(p \lg _{G B_{3} A_{1}}\right)(\mathbf{c}) 2 \mathrm{D}$ flatten pattern for weaving (d) The actual unfolded paper model. (e) The actual folded paper model 
The folded schematic diagram of the combined graphics shows the red, green and blue lines established during folding of 3D-to-2D, in the schematic Fig. 2. The obtained 2D flattened polygon ( $\operatorname{lgg}_{G B_{3} A_{1}}$ ) was cloned to a total of 6 copies, which were linked to neighbouring pieces together by the red, green, and blue folding lines, as shown in Fig. 2a. The unfolding spherical form schematic diagram based on obtained 2D flattened polygon ( $\lg _{G_{3} B_{1}}$ ) is shown in Fig. 2b, the radius of this acquired unfolding hemisphere is $r_{2}$. As $p l_{G E_{1} H_{1} B_{3}}=r_{1}\left(\tan \alpha+\theta \pi /{ }_{180}+\tan \beta\right)$, and $p l_{G E_{1} H_{1} B_{3}}=\frac{\pi}{2} r_{2}$, hence $r_{2}$ was computed by:

$$
r_{2}=\frac{\pi}{2}(\tan \alpha+\theta \pi / 180+\tan \beta) r_{1}
$$

After folding, there are six layers on the two sides, but the middle area requires only the middle area to connect the top and bottom area, so the central area is arranged into two layers with minimum picks (Fig. 2c). The following paper model, Fig. 2d and e additionally proved the feasibility. The $2 \mathrm{D}$ pattern is available to be folded to align with the weft direction, warp direction, and diagonal direction. This paper only presents the folding in the weft direction. This 2D flattened diagram was input into the Bok Garment CAD System (Bok, V13) for parametric drawing and making reference points and measurements for transferring into the technical weaving system.

The optimum 2D geometry obtained for production for the 2D on-loom to 3D offloom process sees the off-loom woven 2D geometry, with appropriate weave architectures transformed back to the required $3 \mathrm{D}$ physical product geometries in a seamless woven spherical composite form. Based on the previous study [30], the tightest weave architecture adjacent to a loose weave architecture was arranged in the central and outer areas, respectively; thus, similar weave architectures were set in the same order in the initial spherical forms. This resulted in longer floats on the outer side decreased, nevertheless, shorter floats in the inner circle extended into the outer circle region [30] to obtain a better dome shape. Correspondingly, as shown in Fig. 3a, areas named A, D, $\mathrm{G}, \mathrm{A}_{1}$ (the outer side) are filled with sateen/satin weave architectures, but parts entitled $\mathrm{C}, \mathrm{F}, \mathrm{I}$ and $\mathrm{C}_{1}$ (the inner circle) are filled using plain weave architectures. The different segments were arranged with various weaving architectures as shown in Table 1 . The specialised weave design to production software (hereinafter referred to as SWDP) was applied to transfer the $2 \mathrm{D}$ folded geometry into a $2 \mathrm{D}$ on-screen representational format. After generating the drawings of geometric conversion results with artificial boundary lines in Bok, SWDP is used to draw a closed area based on the calculated boundary line, then fill in the colours and arrange different weaves depending on the colours. The 2D pattern with closed areas and artificial boundary lines were drawn in EAT 3D, as shown in Fig. 3b. The weaving architectures were generated in the advanced specialised software of EAT 3D employing the visual design process of cross-sectional weft/warp for optimum tailoring. The EAT 3D also bridges the translation of design communication with the loom for the varying production parameters such as shuttle(s) movement, reed location, take-up/let-off speed.

The cross-sectional warp direction is shown in Fig. 4a, the ends indicated by the yellow dashed line need to be cut off after removal from the loom. In the $\mathrm{E}$ and $\mathrm{H}$ areas, the last and first picks stitched between the second and third layer and fourth and fifth layer, respectively. The shuttle arrangements are shown in Fig. 4b, three shuttles are exploited to ensure separated six layers at the bottom area. The cross-section-related related segment letters were highlighted as red in Fig. $3 \mathrm{a}$. 


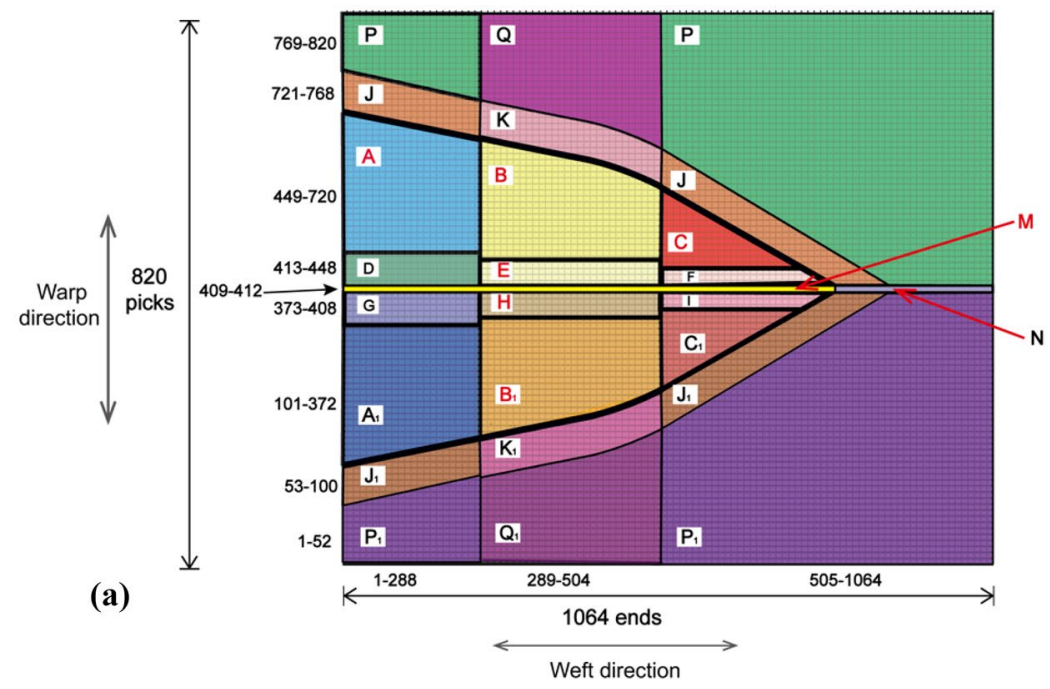

(b)

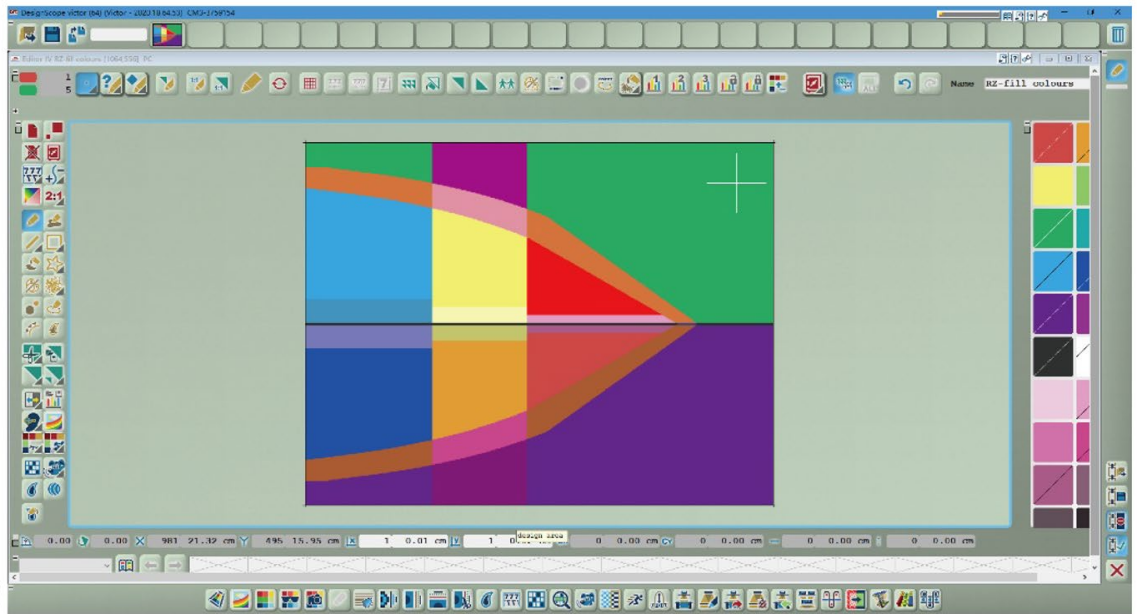

Fig. 3 (a) 2D flatten graphical pattern for the weaving architecture arrangements (b) The screenshot of 2D flatten pattern drawn in the EAT 3D software

To make the final woven sample size meet the predetermined design, the pre-trial weaving was required to be tested in advance. As a result, the final weaving sample dimensions were computed by:

$$
D_{f}=D_{d} / \frac{D_{d}}{D_{p t}}
$$

where $D_{f}$ is the final weaving sample dimension, $D_{d}$ and $D_{p t}$ are design dimensions and the measured dimension of the pre-trial weaving test, respectively.

Similarly, the final weaving density was obtained by: 
Table 1 The weaving architectures arrangements in different segments

\begin{tabular}{|c|c|c|c|c|c|}
\hline $\begin{array}{l}\text { Seg- } \\
\text { ments }\end{array}$ & Filled weaving architectures & Segments & $\begin{array}{l}\text { Filled weaving archi- } \\
\text { tectures }\end{array}$ & $\begin{array}{l}\text { Seg- } \\
\text { ments }\end{array}$ & $\begin{array}{l}\text { Filled weaving archi- } \\
\text { tectures }\end{array}$ \\
\hline $\mathrm{A}, \mathrm{A}_{1}$ & 6L 6 end Sateen & $\mathrm{F}$ & $\begin{array}{l}\text { 6L Plain (first pick } \\
\text { stitched) }\end{array}$ & $\mathrm{K}, \mathrm{K}_{1}$ & $\begin{array}{l}\text { 6L Plain Interchang- } \\
\text { ing }\end{array}$ \\
\hline $\begin{array}{l}\mathrm{B}, \mathrm{B}_{1}, \mathrm{P} \\
\mathrm{P}_{1}\end{array}$ & 6L 2/2 Twill & G & $\begin{array}{l}\text { 6L } 6 \text { end Sateen (last } \\
\text { pick stitched) }\end{array}$ & M & 2L Plain \\
\hline $\begin{array}{c}\mathrm{C}, \mathrm{C}_{1}, \mathrm{Q} \\
\mathrm{Q}_{1}\end{array}$ & 6L Plain & $\mathrm{H}$ & $\begin{array}{l}\text { 6L 2/2 Twill (last } \\
\text { pick stitched) }\end{array}$ & $\mathrm{N}$ & $\begin{array}{l}\text { 2L Plain Interchang- } \\
\text { ing }\end{array}$ \\
\hline $\mathrm{D}$ & $\begin{array}{l}\text { 6L } 6 \text { end Sateen (first pick } \\
\text { stitched) }\end{array}$ & I & $\begin{array}{l}\text { 6L Plain (last pick } \\
\text { stitched) }\end{array}$ & & \\
\hline $\mathrm{E}$ & $\begin{array}{l}\text { 6L } 2 / 2 \text { Twill (first pick } \\
\text { stitched) }\end{array}$ & $\mathrm{J}, \mathrm{J}_{1}$ & $\begin{array}{l}\text { 6L } 2 / 2 \text { Twill-Inter- } \\
\text { changing }\end{array}$ & & \\
\hline
\end{tabular}

$$
W D_{f}=W D_{d} / \frac{W D_{d}}{W D_{p t}}
$$

where $W D_{f}$ is the final sample weaving density, $W D_{d}$ and $W D_{p t}$ are design weaving density and measured weaving density of the pre-trial test, respectively. Notably, if the computed weaving density is too loose or too dense to weave, the pre-trial weaving test and the calculation process should be repeated after re-designing $W D_{d}$. In this research, the design weaving density $\left(W D_{d}\right)$ and final sample weaving density $\left(W D_{f}\right)$ were 31 wefts/cm and 52 wefts/cm, respectively.

\section{Results and Discussions}

The dimensions of the unfolded 3D spherical sample were $20.5 \mathrm{~cm}$ (diameter), $20.7 \mathrm{~cm}$ (diameter), $10.7 \mathrm{~cm}$ (radius), respectively. Figure 5 shows that the final 3D woven sample is an approximate hemisphere.

The origami principle is an ancient folded paper technique; in recent decades, the origami principle is applied in various engineering areas. Sun et al. [31] developed an adaptive space capture approach based on the origami principle. The Miuraori tessellated folding pattern was studied and proposed as a reprogrammable mechanical metamaterial [32]. It was also used in the biological area, such as 3D DNA origami structures for drug delivery and Soft Matter and (Bio-)Nanosciences [33]. According to the origami principle, Li-Ju Tsai [34] developed a fully fashioned on-loom 3D woven box structure employing conventional weaving technology. Hence, the origami technique has enormous possibilities for multifaceted applications. This research innovatively combined the origami technique and its geometric principles with advanced manufacturing weaving technology and software to produce the shaped spherical forms based on the real-time data-design and conventional layer level weaving arrangements. This positive origami geometry process not only could be used in the bra cup area and clothing industry, but also much possible to be induced in various engineering industries.

The literature on 3D shaped weaving has highlighted works on 3D shell fabrics, 3D woven nodal truss structures, and 3D dome shapes. The 3D woven shell form technique was constructed to the modifications of take-up and let-off mechanisms [35]. Smith also 
(a)

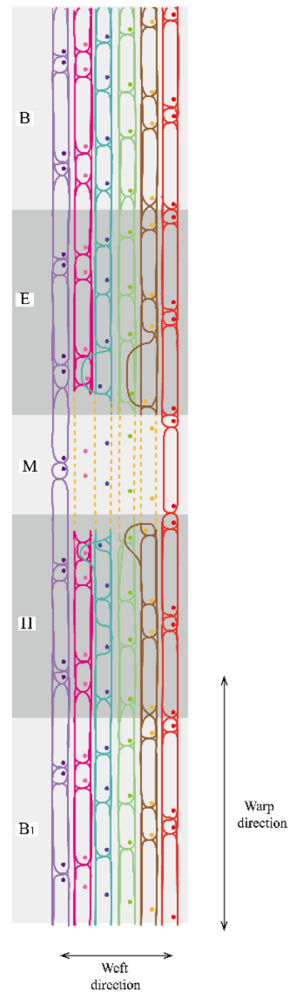

(b)

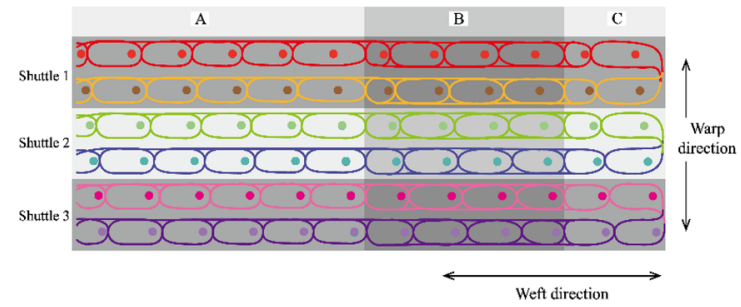

Fig. 4 (a) The cross-section of the sample warp direction (b) The cross-section of the sample weft direction

developed a calculation for computer aiding the yarn interlockings and fibre-yarn crosssection for the 3D nodal fibres [36]. Taylor and Chen [37] presented and defined the variables aligned to a generic process for adaptation of greater nodal configurations. Consideration to geometry (3D) conversion process (2D), elementary 3D weave architectures for the production of the T-shaped 3D woven nodal structure (T-3DWNS) [38] and its derivatives [39]. The technical foundation of the 3D dome shape manufacture was built by Chen, for instance, pitch design, adding the device changed the take-up mechanism for lower weft density [40], and combinations of different weave architecture floats caused yarn height difference [30] aiding the formation, the production of the dome shape. This research focuses on manufacturing the woven spherical form through on-loom folding through to unfolding once removed from the loom. The whole process required real-time data-driven parameters, as presented for the whole product geometric conversion to textile design (woven) to textile production-manufacture process, known as 3D-to-2D-to-3D. This data-driven consideration builds the production for weaving foundations for sportswear-sports bra, as the sports bra required the anthropometric measured data. The 3D-to-2D-to-3D spherical form procedure offers a valuable paradigm for further bra cup forms and dimensions for their weaving manufacture, as shown in Fig. 6.

The objectives of this research, to produce real-time data-driven spherical 3D woven composites combining the origami folding technique in the design for production stages of constructed woven textiles using the latest weaving technology, MS-100 meets the primary 


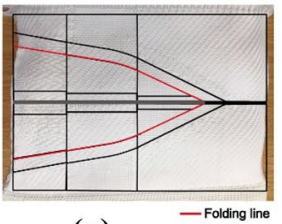

(a)

— Folding line

(b)
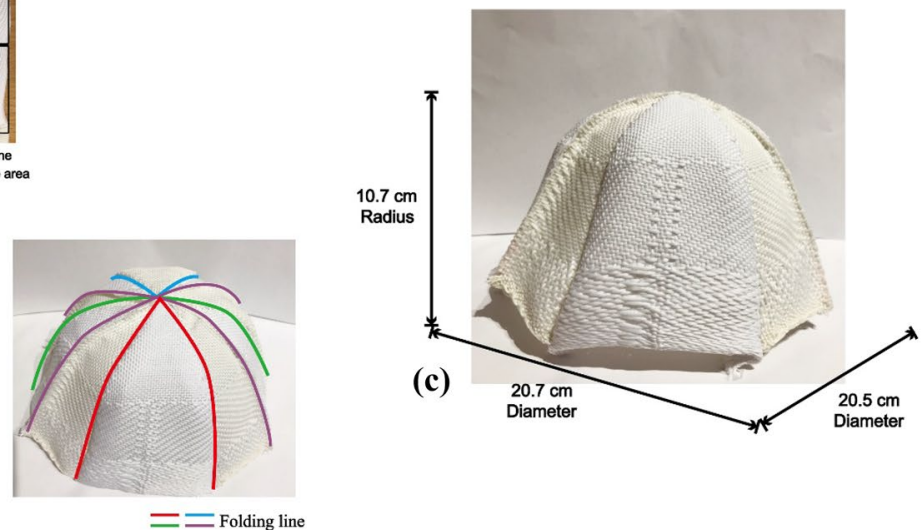

Fig. 5 (a) The folded 2D woven form (b) The unfolded 3D spherical form (c) The dimensions of the unfolded sample

aim, to implement protection and performance within the clothing industry for apparel items. The success of the 3D-to-2D-to-3D process using the cross-platform digital software to obtain accurate size and shaped composites aids the need for the manufacture of wellfitted garments, improving the fit and inherent comfort. The various multi-application digital systems employed in the process generated an accurate 3D and 2D parametric geometry foundational database. The data-driven consideration with the help of a cross-platform system would also enhance and develop the design and geometry route (3D-to-2D-to-3D process) for the technical weaving technology. The sportswear application requires high-
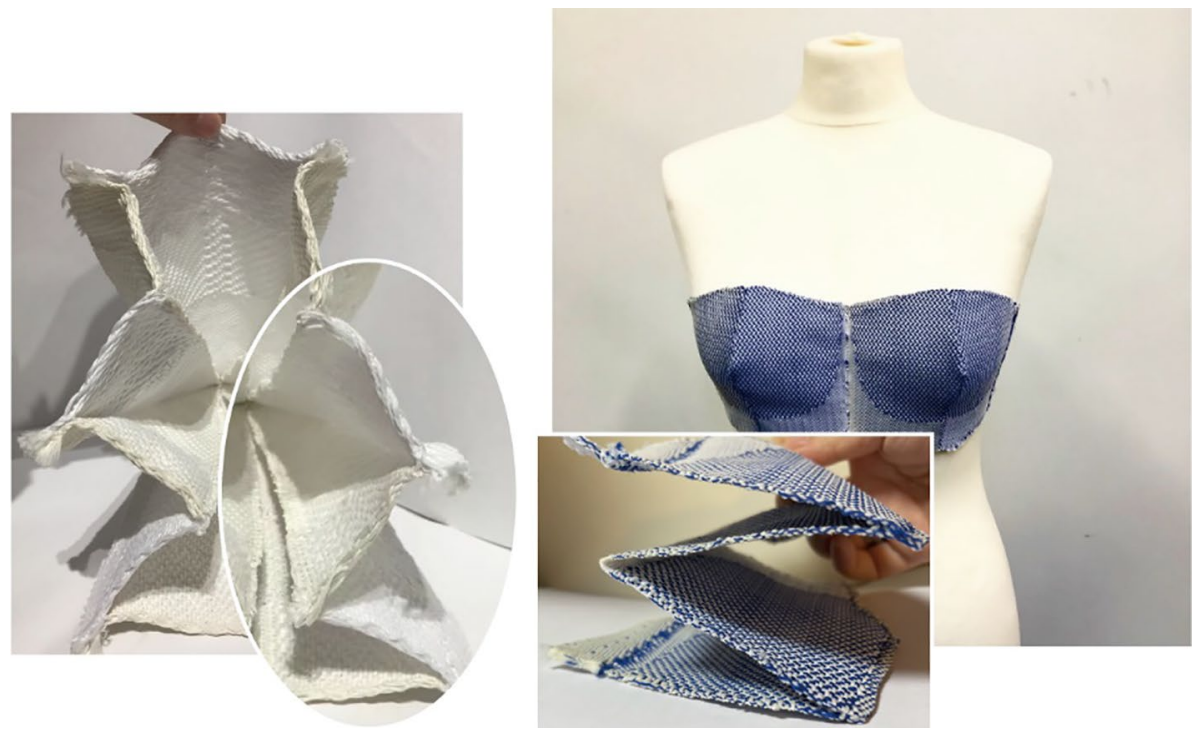

Fig. 6 The cross-sections of folding spherical form and folding bra front block 
performance materials and longevity of, therefore, future works are recommended to compare the property testing approaches, such as thermal comfort, tensile strength, impact testing, and flexural testing. This paper only presents the fold direction of the 3D woven spherical form aligned to/with the weft direction. The manufacturing principles and parameters for on-loom folding in the warp and diagonally to directions are comparable production approaches in current further works.

\section{Conclusions}

This research innovatively presented to fold a seamless spherical form based on the origami technique through the 3D-to-2D-to-3D weave design for weave production process [37-39]. The process employed the cross-platform CAD/CAM software to create a parametric folded and unfolded spherical composite. This 3D woven spherical form is aimed at end textile product applications such as the sports bra and other spherical shape clothing parts, located in areas such as hips, elbows, and knees. In addition to the sportswear-sports bra focus, and other relative woven apparel items, this folded and unfolded 3D woven spherical form has potential application in: civil engineering industries, aerospace (in consideration of the radome) to furniture counterparts.

Funding The authors received no financial support for the research, authorship, and/or publication of this article.

Data Availability The datasets generated during and/or analysed during the current study are available from the corresponding author on reasonable request.

\section{Declarations}

Conflicts of Interest The authors declare that there is no conflict of interest.

Open Access This article is licensed under a Creative Commons Attribution 4.0 International License, which permits use, sharing, adaptation, distribution and reproduction in any medium or format, as long as you give appropriate credit to the original author(s) and the source, provide a link to the Creative Commons licence, and indicate if changes were made. The images or other third party material in this article are included in the article's Creative Commons licence, unless indicated otherwise in a credit line to the material. If material is not included in the article's Creative Commons licence and your intended use is not permitted by statutory regulation or exceeds the permitted use, you will need to obtain permission directly from the copyright holder. To view a copy of this licence, visit http://creativecommons.org/licenses/by/4.0/.

\section{References}

1. Shishoo, R.: Materials and production technology. In: Shishoo, R. (ed) Textile for sportswear, pp. 1-16. Woodhead Publishing, Cambridge (2015)

2. Hardaker, C.H.M., Fozzard, G.J.W.: The bra design process - a study of professional practice. Int. J. Cloth. Sci. Technol. 9, 311-325 (1997)

3. Hadi, M.S.A.A.: Sports Brassiere: Is it a solution for mastalgia? The Breast J. 6(6), 407-409 (2003)

4. Smith, R.L., Pruthi, S., Fitzpatrick, L.A.: Evaluation and management of breast pain. Mayo Clin. Proc. 79, 353-372 (2004) 
5. Mason, B.R., Page, K., Fallon, K.: An analysis of movement and discomfort of the female breast during exercise and the effects of breast support in three cases. J. Sci. Med. Sport. 2(2), 134-144 (1999)

6. Zhou, J., Yu, W., Ng, S.P.: Methods of studying breast motion in sports bras: a review. Text. Res. J. 81(12), 1234-1248 (2011)

7. White, J., Scurr, J.: Evaluation of professional bra fitting criteria for bra selection and fitting in the UK. Ergonomics. 55(6), 704-711 (2012)

8. Lorentzen, D., Lawson, L.: Selected sports bras: a biomechanical analysis of breast motion while jogging. Physician Sports Med. 15, 128-139 (1987)

9. Scurr, J., White, J., Hedger, W.: Breast displacement in three dimensions during the walking and running gait cycles. J. Appl. Biomech. 25(4), 322-329 (2009)

10. Troynikov, O., Watson, C.: Knitting technology for seamless sportswear. In: Shishoo, R. (ed.) Textiles for Sportswear, pp. 95-117. Woodhead Publishing, Cambridge (2015)

11. Bartels, V.T.: Physiological comfort of sportswear. In: Shishoo, R. (ed.) Textiles in Sport, pp. 177-203. Woodhead Publishing, Cambridge (2015)

12. Ashdown, S.P.: Improving body movement comfort in apparel. In: Song, G. (ed.) Improving Comfort in Clothing, pp. 278-302. Woodhead Publishing, Cambridge (2011)

13. Fan, J.: Physiological comfort of fabrics and garments. In: Fan, J., Hunter, L. (eds.) Engineering Apparel Fabrics and Garments, pp. 201-250. Woodhead Publishing Limited in association with The Textile Institute, Cambridge (2009)

14. Zhou, J., Yu, W., Ng, S.P.: Studies of three-dimensional trajectories of breast movement for better bra design. Text. Res. J. 82(3), 242-254 (2012)

15. Chen, X., Yang, D.: Use of 3D angle-Interlock woven fabric for seamless female body armor: Part 1: Ballistic Evaluation. Text. Res. J. 80(15), 1581-1588 (2010)

16. Smith, C.J., Havenith, G.: Body mapping of sweating patterns in male athletes in mild exerciseinduced hyperthermia. Eur. J. Appl. Physiol. 111(7), 1391-1404 (2011)

17. Taylor, N.A.S., Machado-Moreira, C.A.: Regional variations in transepidermal water loss, eccrine sweat gland density, sweat secretion rates and electrolyte composition in resting and exercising humans. Extreme Physiology Med. 2(1), 1-29 (2013)

18. Formenti, D., et al.: Thermal imaging of exercise-associated skin temperature changes in trained and untrained female subjects. Ann. Biomed. Eng. 41(4), 863-871 (2013)

19. Jetavat, D.: Near net shape preforming by 3D weaving process. University of Manchester, Manchester (2012)

20. Chen, X., Yang, D.: Use of three-dimensional angle-interlock woven fabric for seamless female body armor: Part II: Mathematical Modeling. Text. Res. J. 80(15), 1589-1601 (2010)

21. Zheng, R., Yu, W., Fan, J.: Development of a new Chinese bra sizing system based on breast anthropometric measurements. Int. J. Ind. Ergon. 37(8), 697-705 (2007)

22. Lee, H.Y., Hong, K., Kim, E.A.: Measurement protocol of women's nude breasts using a 3D scanning technique. Appl. Ergon. 35(4), 353-359 (2004)

23. Pei, J., Park, H., Ashdown, S.P.: Female breast shape categorization based on analysis of CAESAR 3D body scan data. Text. Res. J. 89(4), 590-611 (2019)

24. Shi, Y., Shen, H., Taylor, L.W., Cheung, V.: The impact of age and body mass index on a bra sizing system formed by anthropometric measurements of Sichuan Chinese females. Ergonomics. 63(11), 1434-1441 (2020)

25. Sayem, A.S.M., Kennon, R., Clarke, N.: 3D CAD systems for the clothing industry. Int. J. Fash. Des. Technol. Educ. 3(2), 45-53 (2010)

26. Sayem, A.S.M., Kennon, R., Clarke, N., Hayes, S.: The effect of link-length and vertex angle on mesh generation and pattern flattening for virtual clothin. Int. J. Cloth. Sci. Technol. 28(4), 503-515 (2016)

27. Sayem, A. S. M., Kennon, R., Clarke, N.: 3D grading and pattern unwrapping technique for loosefitting shirt, Part 1: Resizable Design Template. J. Text. Apparel Technol. Manag. 8(4), [Online] North Carolina State University, USA (2014a)

28. Sayem, A. S. M., Kennon, R., Clarke, N.: 3D grading and pattern unwrapping technique for loosefitting Shirt, Part 2: Functionality. J. Text. Apparel Technol. Manag. 8(4), [Online] North Carolina State University, USA (2014b)

29. Sayem, A.S.M., Kennon, R., Clarke, N.: Resizable trouser template for virtual design and pattern flattening. Int. J. Fash. Des. Technol. Educ. 5(1), 55-65 (2012)

30. Yang, D., Tayyar, A.E., Chen, X.: Parametric study of the weave combination on the moldability of dome-shaped fabrics. Text. Res. J. 89(2), 150-161 (2019)

31. Sun, W.: Adaptive space debris capture approach based on origami principle. Int. J. Adv. Robot. Syst. 16(6), 1-11 (2019) 
32. Silverberg, E.: Using origami design principles to fold reprogrammable mechanical metamaterials. Science (American Association for the Advancement of Science). 345(6197), 647-650 (2014)

33. Loescher, S., Groeer, S., Walther, A.: 3D DNA origami nanoparticles: from basic design principles to emerging applications in soft matter and (Bio-)Nanosciences. Angew. Chem.-Int. Edit. 57(33), 1043610448 (2018)

34. Tsai, L.J.: A study of creating integrated 3D open box fabric using conventional weaving technology. The University of Manchester, Manchester (2014)

35. Busgen, A.: Woven fabric having a bulging zone and method and apparatus of forming same (Patent) (1999)

36. Smith, M.: CAD/CAM and geometric modelling algorithms for 3D woven multi-layer nodal textile structures. The University of Manchester, Manchester (2009)

37. Taylor, L.W., Chen, X.: Generic production process for 3D woven nodal elementary and derivative structures. J. Compos Mater. 50(29), 4103-4121 (2016)

38. Taylor, L.W., Chen, X., Smith, M.A.: Production principles for a T-shaped 3D woven nodal structure (T-3DWNS). J. Text. Inst. 108(1), 10-19 (2017)

39. Taylor, L.W., Chen, X.: Nodal three-dimensional woven textiles. In: Chen, X. (ed.) Advances in 3D Textiles, pp. 99-122. Woodhead Publishing, Cambridge (2015)

40. Chen, X., Tayyar, A.E.: Engineering, manufacturing, and measuring 3D domed woven fabrics. Text. Res. J. 73(5), 375-380 (2003)

Publisher's Note Springer Nature remains neutral with regard to jurisdictional claims in published maps and institutional affiliations. 